\title{
A Miocene breeding ground of an extinct baleen whale (Cetacea: Mysticeti)
}

\author{
Cheng-Hsiu Tsai ${ }^{\text {Corresp. } 1}$ \\ ${ }^{1}$ Department of Geology and Paleontology, National Museum of Nature and Science, Tsukuba, Japan \\ Corresponding Author: Cheng-Hsiu Tsai \\ Email address: craniata@gmail.com
}

Locating breeding sites is definitely a key to understanding the ecological requirements and maintaining the sustainability of populations/species. Here I re-examined published specimens of an extinct baleen whale, Parietobalaena yamaokai, from the lower part of Itahashi Formation (16.1-15.6 Ma, Middle Miocene) in Shobara, Hiroshima, Japan. A critical and previously unnoticed feature, the open suture between the supraoccipital and exoccipital, in one specimen indicates the preservation of a very young individual-under six months old and even close to a new-born calf. Given the occurrence of a new-born whale and relatively abundant assemblage of Parietobalaena yamaokai, I propose a previously hidden and unknown breeding ground for the extinct baleen whale, $P$. yamaokai, in the Middle Miocene of Shobara (16.1-15.6 Ma), Hiroshima. Discovery of paleo-breeding sites of extinct populations/species should further help us to understand biological extinctions from a long-term perspective as conservation paleobiology aims to offer new insights into policy making for conserving endangered populations/species. 
1 A Miocene breeding ground of an extinct baleen whale (Cetacea: Mysticeti)

2

3 Cheng-Hsiu Tsai

4 Department of Geology and Paleontology, National Museum of Nature and Science, Tsukuba, 5 Japan

6 craniata@gmail.com; cheng-hsiu.tsai@otago.ac.nz

\section{Abstract}

9 Locating breeding sites is definitely a key to understanding the ecological requirements and maintaining the sustainability of populations/species. Here I re-examined published specimens of an extinct baleen whale, Parietobalaena yamaokai, from the lower part of Itahashi Formation (16.1-15.6 Ma, Middle Miocene) in Shobara, Hiroshima, Japan. A critical and previously unnoticed feature, the open suture between the supraoccipital and exoccipital, in one specimen indicates the preservation of a very young individual-under six months old and even close to a new-born calf. Given the occurrence of a new-born whale and relatively abundant assemblage of Parietobalaena yamaokai, I propose a previously hidden and unknown breeding ground for the extinct baleen whale, P. yamaokai, in the Middle Miocene of Shobara (16.1-15.6 Ma), Hiroshima. Discovery of paleo-breeding sites of extinct populations/species should further help us to understand biological extinctions from a long-term perspective as conservation paleobiology aims to offer new insights into policy making for conserving endangered populations/species.

\section{Introduction}

Finding out the previously unknown breeding sites definitely is crucial for acquiring critical information for the conservation purpose of extant species. However, it is equally important to locate breeding grounds of extinct populations/species in the deep past (i.e. conservation paleobiology, see Dietl et al., 2015; Barnosky et al., 2017). This will provide critical information that can be used to develop more insightful conservation policies by integrating long-term perspectives that may be relevant to rapidly changing environments. For example, the eastern North Pacific population of gray whales, Eschrichtius robustus, is currently large and stable, and even becomes an attraction for whale watching. In fact, this population used 
32 to be close to the brink of extinction in the early $20^{\text {th }}$ century, but the population recovered, 33 thanks to the well-known breeding sites so that it facilitated the recovery and protection of a 34 nearly extinct population. On the contrary, the status of the western North Pacific population is 35 more uncertain, with their population down to 100 individuals, it could face the similar as their 36 North Atlantic counterparts (Mead and Mitchell, 1984). As a result, discovery of a prehistoric 37 breeding site for the western North Pacific population (Tsai et al., 2014) should then bring a new 38 consideration of how to further maintain and even recover the population of a near-extinct 39 population.

Here, I report a Miocene breeding site for an extinct baleen whale, Parietobalaena yamaokai (Cetacea: Mysticeti) from Shobara, Hiroshima, Japan (16.1-15.6 Ma, Itahashi

42 Formation, Bihoku Group). The finding of a previously unknown breeding ground of an extinct 43

44 45 46 47

baleen whale should give us an opportunity for a new look at extinction event and further understand the ecological and evolutionary response of species to environmental changes from a long-term perspective as the conservation paleobiology aims to offer a new aspect for policy making when concerning the conservation of endangered populations/species.

\section{Materials \& Methods}

Published specimens of Parietobalaena yamaokai were re-examined, including HMNF00023, HMN-F00024 (two accession numbers belong to the same individual, which was assigned as the type specimen), HMN-F00042, HMN-F00044, HMN-F00054, HMN-F00127 (all described in one paper; Otsuka and Ota, 2008), HMN-F00004 (Kimura et al., 2010), and HMNF00640 (Kimura et al., 2011). All specimens were recovered from the same geological horizonlower part of the Itahashi Formation, Bihoku Group; according to the occurrence of some nannofossils, such as Sphenolithus heteromorphus and Helicosphaera ampliaperta, this horizon corresponds to the NN4 biozone in the Middle Miocene (Martini, 1971; Yamamoto, 1999) and spans roughly from 16.1 to $15.6 \mathrm{Ma}$.

Determination of ontogenetic ages follows the results of studying early juvenile specimens and calves of extant Eschrichtius robustus (gray whale), Balaenoptera acutorostrata (minke whale), B. physalus (fin whale), and Megaptera novaeangliae (humpback whale) (Walsh and Berta, 2011); here, I included a fetal specimen of the blue whale, Balaenoptera musculus (USNM 268001), to show the open suture between the supraoccipital and exoccipital and 
63 facilitate the comparison with a very young individual of Parietobalaena yamaokai (Fig. 1). The

64 phylogenetic placement of Parietobalaena yamaokai remains uncertain; for example,

65 phylogenetically, P. yamaokai can be a balaenopteroid (Marx and Fordyce, 2015) or a

66 "cetothere" sensu lato (Boessenecker and Fordyce, 2016). Given that the position of P. yamaokai

67 is a balaenopteroid in the Marx and Fordyce or belongs to a sister lineage of balaenopteroids (a

68

69

70

71

72

73

74

75

82

83

84

85

86

87

88

89

90

91

92 93

cetothere sensu lato) in the Boessenecker and Fordyce 2016, the sequence of ossification and the ontogenetic age inferred from the fusion of occipital joints in other extant balaenopteroids (the gray whale, minke whale, fin whale, and humpback whale are all balaenopteroids) should still be a reliable proxy for P. yamaokai.

In addition, the body size could be an alternative approach to estimate the ontogenetic age, although the growth curve or full-grown size of Parietobalaena yamaokai remains unknown. I use two equations, both of which rely on the bizygomatic width of the skull to reconstruct the body size specifically for baleen whales (Lambert et al., 2010: y (body length) = $8.209 * x$ (bizygomatic width) +66.69 ; Pyenson and Sponberg, 2011: log (body length) $=$ $0.92 *(\log ($ bizygomatic width $)-1.64)+2.67)$, to assess the total length of HMN-F00127. Given the preserved condition, the exact bizygomatic width of HMN-F00127 is uncertain, but likely approximates $30 \mathrm{~cm}$. In order to have a better understanding of their body size, a larger individual, HMN-F00042, whose bizygomatic width approaches but slightly less than $50 \mathrm{~cm}$, was also estimated.

Institutional abbreviations. HMN, The Hiwa Museum for Natural History, Shobara, Hiroshima, Japan; USNM, National Museum of Natural History, Smithsonian Institution, USA.

\section{Results}

New observations on the published specimens of Parietobalaena yamaokai show that several reported fossils are juvenile specimens, although it remains problematic for clearly identifying exact ontogenetic ages of each fossil specimen. However, one specimen (HMNF00127) appears to be a very young individual, under six months old, judging from the open suture between the supraoccipital and exoccipital (Fig. 1) as the sequence and timing of the occipital ossification in the extant balaenopteroids provide an applicable proxy (Walsh and Berta, 2011). Given the preserved morphology of the supraoccipital in HMN-F00127, it is 
94 slightly eroded, but the overall edge remains intact, in turn, excluding the possibility of damage. 95 Likewise, the separation between the supraoccipital and exoccipital of HMN-F00127 is unlikely 96 to result from some unusual occipital fenestrations in some cetaceans (Gao and Gaskin, 1996; 97 Trimble and Praderi, 2008), leading to the conclusion that the open suture is genuine, which 98 could be comparable to a fetal/new-born blue whale, Balaenoptera musculus as shown in Fig.1. 99 Additionally, given the estimated bizygomatic width $(30 \mathrm{~cm})$, the body size for HMN100 101 102 referable feature to estimate the ontogenetic age (Moran et al., 2014), but can only be a rough proxy. With $50 \mathrm{~cm}$, the body size of HMN-F00042 ranges from $477 \mathrm{~cm}$ (Lambert et al 2010 equation) to $766 \mathrm{~cm}$ (Pyenson and Sponberg 2011 equation).

Discussion

HMN-F00127 represents a rare baleen whale fossil whose ontogenetic age was previously unrecognized and actually can be genuinely determined the ontogenetic age to some extent - under six months old, given the open suture between the supraoccipital and exoccipital.

112 Furthermore, the supraoccipital is virtually floating, lacking a firm contact with surrounding

113 bones (e.g. exoccipital and parietal) and in turn suggesting a much younger developmental stage

114 (likely to be close to a new-born calf?), comparable to a fetal specimen of blue whale, Balaenoptera musculus (Fig. 1). In addition, a relatively abundant assemblage of Parietobalaena

116 yamaokai (Otsuka and Ota, 2008; Kimura et al., 2010, 2011) from the same geological horizon

117 (Itahashi Formation, Bihoku Group) and geographical area (Shobara, Hiroshima) invites a 118 sensible interpretation: the presence of a previously unknown Miocene breeding/calving site for 119 baleen whales in Shobara, Hiroshima. Likewise, the reconstruction of paleogeography and 120 paleoclimatology of the area where HMN-F00127 and other specimens of P. yamaokai were 121 found (Fig. 2; also see Noda and Goto, 2004) suggests a relatively protected and possibly an 122 ideal locality for breeding purposes as extant baleen whales seek for calving sites (Hindell, 2009; 123 Rayment et al., 2015). 
125 likely differs from adults substantially in extant baleen whales. The underlying heterochronic

126 process that affects the evolutionary history and developmental pattern of Parietobalaena

127 yamaokai remains unidentified: clades showing paedomorphic neoteny have similar morphology,

128 which allows reliable identification based on juvenile specimens (e.g. the pygmy right whale,

129 Caperea marginata; Tsai and Fordyce 2014a, 2014b). By contrast, peramorphic acceleration

130 clades show disparate morphologies between juveniles and adults, hence likely resulting in

131 misleading interpretations (e.g. the humpback whale, Megaptera novaeangliae; Tsai and

132 Fordyce, 2014a, 2014b; or, an extinct eomysticetid, Waharoa ruwhenua; Boessenecker and

133 Fordyce, 2015), making the conspecific confirmation of fossil specimens between juveniles and

134 adults problematic. In addition, several baleen whale species apart from P. yamaokai were found

135 from the same locality, such as Diorocetus shobarensis and Hibacetus hirosei, complicating the

136 scenario of species identification of juvenile specimens. As juvenile identification of

137 Parietobalaena yamaokai and/or other contemporaneous baleen whales in Shobara, Hiroshima is

138 beyond the scope of this study, here I follow the interpretations of previous studies on HMN-

139 F00127 as a P. yamaokai (Otsuka and Ota, 2008; Kimura et al., 2010, 2011).

Additionally, it is worth noting that if the estimated body size for HMN-F00127, $313 \mathrm{~cm}$

141 from Lambert et al (2010) equation or $479 \mathrm{~cm}$ from Pyenson and Sponberg (2011) equation, is

142 approximately accurate for a young individual under 6 months old, Parietobalaena yamaokai

143 would have been a middle-sized baleen whale, 12-15 $\mathrm{m}$ when full-grown, similar to the size of

144 extant gray whales, Eschrichtius robustus (see Andrews, 1914; Rice and Wolman, 1971 for

145 references to the size of gray whales). This can be corroborated by a larger, but physically

146 immature specimen HMN-F00042, whose estimated body length is $477 \mathrm{~cm}$ or $766 \mathrm{~cm}$ under

147 different equations. HMN-F00042 may also be a juvenile, ontogenetically older than HMN-

148 F000127, given the presence of several loose and unfused vertebral discs, but unable to further

149 pin down its precise age at present. As a result, if the interpretation on the estimated size and 150 ontogenetic age for HMN-F00127 or HMN-F00042 is correct, it then suggests the existence of

151 large baleen whales (over $10 \mathrm{~m}$ ) in the Middle Miocene (Itahashi Formation, 16.1-15.6 Ma),

152 substantiating the early origin of baleen whale gigantism (Tsai and Kohno, 2016), instead of a

153 recent origin (Slater et al., 2017), albeit the lack of ancestor-descendant relationships to illustrate 
154 the detailed evolution of gigantism for now (see Tsai and Fordyce, 2015 for discussion of 155 ancestor-descendant relationships).

156 Regardless, identifying a possible Miocene breeding site for baleen whales in the

157 northern hemisphere also raises some interesting questions: when, where, and which species of

158 baleen whales initiated the annual, long migration between feeding and calving grounds? If the 159 interpretation in this paper is correct, it then represents the earliest known site (Middle Miocene, 160 16.1-15.6 Ma) for baleen whale breeding in the northern hemisphere (Fig. 3). However, given 161 the presence of a young individual of an Oligocene baleen whale, Waharoa ruwhenua (Cetacea: 162 Eomysticetidae), together with isotopic analyses of other eomysticetid species (for example

163 Tokarahia, Clementz et al., 2014), Waharoa or other eomysticetids may have established a long, 164 latitudinal migration and come to continental waters of the Oligocene of New Zealand for 165 breeding in the southern hemisphere (27.3-25.2 Ma, Boessenecker and Fordyce, 2015). In view 166 of extant baleen whales, annual migration between feeding and breeding sites may not result

167 from long-term evolutionary consequences, but instead ecological factors. In other words, 168 establishment of having regular migrations in baleen whales may occur multiple times. On the 169 other hand, there are several hypotheses, interpreting why baleen whales have long-distance 170 migrations annually, such as thermoregulatory purpose for calves or reducing risk of predation 171 by killer whales, Orcinus orca (Corkeron and Connor, 1999). Accordingly, seeking for suitable

172 breeding and feeding sites and then resulting in annual migrations in baleen whales may have 173 evolved and appeared independently in different lineages, by different ecological causes, and at 174 different geological timings. More fossils and higher resolution of paleo-geographical and paleo175 climatic reconstructions should further test hypotheses presented in this paper and explore more 176 details of behavioral evolution in baleen whales, whose behavioral evolution may shape the 177 direction of evolution in the marine regime as baleen whales are the largest vertebrates in the 178 history of Life.

179

180 Acknowledgements.

181 I thank Tomomi Kiyoshi, Hitoshi Ohzawa, Yoshio Furukawa, Takato Ueda for inviting and 182 encouraging to study HMN specimens; James Mead, Charles Potter, John Ososky, Nicholas 183 Pyenson, and David Bohaska for collection access and allowing photography (USNM 184 specimens); Nobumichi Tamura for illustrating the life restoration (Fig. 3); the handling editor 
185 John Hutchinson for helpful guidance; Brian Beatty and one anonymous reviewer for 186 constructive comments and suggestions; Megumi Saito-Kato and Atsushi Yabe for discussing 187 paleogeography of Japan; James Mead (Washington DC) for accommodating at the "Happiness 188 Hotel" during various research visits.

189

190

References

191

Andrews RC. 1914. Monographs of the Pacific Cetacea. I. The California gray whale

192 (Rhachianectes glaucus Cope). Memoirs of the American Museum of Natural History, Series II 193 1:227-287.

194

Barnosky AD, Hadly EA, Gonzalez P, Head J, Polly PD, Lawing AM, Eronen JT, Ackerly 195 DD, Alex K, Biber E, Blois J, Brashares J, Ceballos G, Davis E, Dietl GP, Dirzo R, 196 Doremus H, Fortelius M, Greene HW, Hellmann J, Hickler T, Jackson ST, Kemp M, Koch PL, Kremen C, Lindsey EL, Looy C, Marshall CR, Mendenhall C, Mulch A, Mychajliw 198 AM, Nowak C, Ramakrishnan U, Schnitzler J, Shrestha KD, Solari K, Stegner L, Stegner 199 MA, Stenseth NC, Wake MH, Zhang Z. 2017. Merging paleobiology with conservation biology to guide the future of terrestrial ecosystems. Science 355:eaah4787 DOI 201 10.1126/science.aah4787

202

Boessenecker RW, Fordyce RE. 2015. Anatomy, feeding ecology, and ontogeny of a

203 transitional baleen whale: a new genus and species of Eomysticetidae (Mammalia: Cetacea) from 204 the Oligocene of New Zealand. PeerJ 3:e1129 DOI 10.7717/peerj.1129

205

206

207

208

209

210

211

212

213

214

Boessenecker RW, Fordyce RE. 2016. A new eomysticetid from the Oligocene Kokoamu Greensand of New Zealand and a review of the Eomysticetidae (Mammalia, Cetacea). Journal of Systematic Palaeontology DOI 10.1080/14772019.2016.1191045.

Clementz MT, Fordyce RE, Peek SL, Fox DL. 2014. Ancient marine isoscapes and isotopic evidence of bulk-feeding by Oligocene cetaceans. Palaeogeography, Palaeoclimatology, Palaeoecology 400:28-40 DOI 10.1016/j.palaeo.2012.09.009.

Corkeron PJ, Connor RC. 1999. Why do baleen whales migrate? Marine Mammal Science 15:1228-1245.

Dietl GP, Kidwell SM, Brenner M, Burney DA, Flessa KW, Jackson ST, Koch PL. 2015. Conservation paleobiology: leveraging knowledge of the past to inform conservation and 
215 restoration. The Annual Review of Earth and Planetary Sciences 43:79-103 DOI

216 10.1146/annurev-earth-040610-133349.

217 Gao A, Gaskin DE. 1996. Nonmetric morphometry of the skull of the harbour porpoise,

218 Phocoena phocoena, in the western North Atlantic and eastern North Pacific. Canadian Journal 219 of Zoology 74:2199-2205.

220 Hindell MA. 2009. Breeding sites. In: Perrin WF, Würsig B, Thewissen JGM, eds. Encyclopedia 221 of Marine Mammals. $2^{\text {nd }}$ edition. Burlington, Academic Press, 156-158.

222 Kimura T, Hasegawa Y, Ohzawa H, Ueda T, Yamaoka, T. 2010. A fossil mysticete from the 223 middle Miocene Bihoku Group, Hiroshima, Japan. Bulletin of the Gunma Museum of Natural 224 History 14:29-36.

225 Kimura T, Hasegawa Y, Ohzawa H, Yamaoka T, Ueda T, Kiyoshi T, Furukawa Y, 226 Sugihara M. 2011. An addition fossil mysticete from the middle Miocene Bihoku Group, 227 Hiroshima, Japan. Bulletin of the Gunma Museum of Natural History 15:81-92.

228 Lambert O, Bianucci G, Post K, de Muizon C, Salas-Gismondi R, Urbina M, Reumer J. 229 2010. The giant bite of a new raptorial sperm whale from the Miocene epoch of Peru. Nature 230 466:105-108 DOI 10.1038/nature09067.

231 Martini E. 1971. Standard Tertiary and Quaternary calcareous nannoplankton zonation. In 232 Proceedings of the $2^{\text {nd }}$ Planktonic Conference, Roma, 1970, p.739-785.

233 Marx FG, Fordyce RE. 2015. Baleen boom and bust: a synthesis of mysticete phylogeny, 234 diversity and disparity. Royal Society Open Science 2:140434 DOI 10.1098/rsos.140434

235 Mead J, Mitchell ED. 1984. Atlantic gray whales. In: Jones ML, Swartz SL, Leatherwood S, 236 eds. The Gray Whale. New York, Academic Press, 33-53.

237 Moran MM, Bajpai S, George JC, Suydam R, Usip S, Thewissen JGM. 2015. Intervertebral 238 and epiphyseal fusion in the postnatal ontogeny of cetaceans and terrestrial mammals. Journal of 239 Mammalian Evolution 22:93-109.

240 Noda Y, Goto M. 2004. Paleogeographic maps of the Japanese Islands and their application to 241 exhibition of the Fukui Prefectural Dinosaur Museum. Memoir of the Fukui Prefectural 242 Dinosaur Museum 3:47-63.

243 Otsuka H, Ota Y. 2008. Cetotheres from the early Middle Miocene Bihoku Group in Shobara 244 District, Hiroshima Prefecture, West Japan. Miscellaneous Reports of the Hiwa Museum for 245 Natural History 49:1-66. 
246 Pyenson ND, Sponberg SN. 2011. Reconstructing body size in extinct crown Cetacea (Neoceti)

247 using allometry, phylogenetic methods and tests from the fossil record. Journal of Mammalian

248 Evolution 18:269-288 DOI 10.1007/s10914-011-9170-1.

249 Rayment W, Dawson S, Webster T. 2015. Breeding status affects fine-scale habitat selection of 250 southern right whales on their wintering grounds. Journal of Biogeography 42:463-474 DOI $25110.1111 /$ jbi.12443.

252 Rice DW, Wolman AA. 1971. The life history and ecology of the gray whale (Eschrichtius

253 robustus). Special Publication No. 3, The American Society of Mammalogists, Olympia,

254 Washington pp. 142.

255 Slater GJ, Goldbogen JA, Pyenson ND. 2017. Independent evolution of baleen whale 256 gigantism linked to Plio-Pleistocene ocean dynamics. Proceeding of the Royal Society B

257 288:20170546 DOI 10.1098/rspb.2017.0546.

258 Trimble M, Praderi R. 2008. Assessment of nonmetric skull characters of the Franciscana 259 (Pontoporia blainvillei) in determining population differences. Aquatic Mammals 34:338-348.

260 Tsai C-H, Fordyce RE. 2014a. Disparate heterochronic processes in baleen whale evolution.

261 Evolutionary Biology 41:299-307 DOI 10.1007/s11692-014-9269-4.

262 Tsai C-H, Fordyce RE. 2014b. Juvenile morphology in baleen whale phylogeny.

263 Naturwissenschaften 101:765-769 DOI 10.1007/s00114-014-1216-9.

264 Tsai C-H, Fordyce RE. 2015. Ancestor-descendant relationships in evolution: origin of the

265 extant pygmy right whale, Caperea marginata. Biology Letters 11:20140875 DOI

$26610.1098 / \mathrm{rsbl} .2014 .0875$.

267 Tsai C-H, Kohno N. 2016. Multiple origins of gigantism in stem baleen whales. The Science of 268 Nature (Naturwissenschaften) 103:89 DOI 10.1007/s00114-016-1417-5.

269 Tsai C-H, Fordyce RE, Chang CH, Lin LK. 2014. Quaternary fossil gray whales from Taiwan. 270 Paleontological Research 18:82-93 DOI 10.2517/2014PR009.

271 Walsh B, Berta A. 2011. Ossification of balaenopteroid mysticetes. The Anatomical Record 272 294:391-398 DOI 10.1002/ar.21340.

273 Yamamoto M. 1999. Lithofacies and calcareous nannofossils of the Miocene Bihoku Group in

274 the Saijogawa area, Shobara, Hiroshima, Japan. Earth Science 53:202-216 (in Japanese).

275

276 
277 Figure 1. Open suture between the supraoccipital and exoccipital in (a) a fossil baleen whale, 278 HMN-F00127 (Parietobalaena yamaokai) and (b) a fetal specimen of blue whale, Balaenoptera 279 musculus (USNM 268001).

280

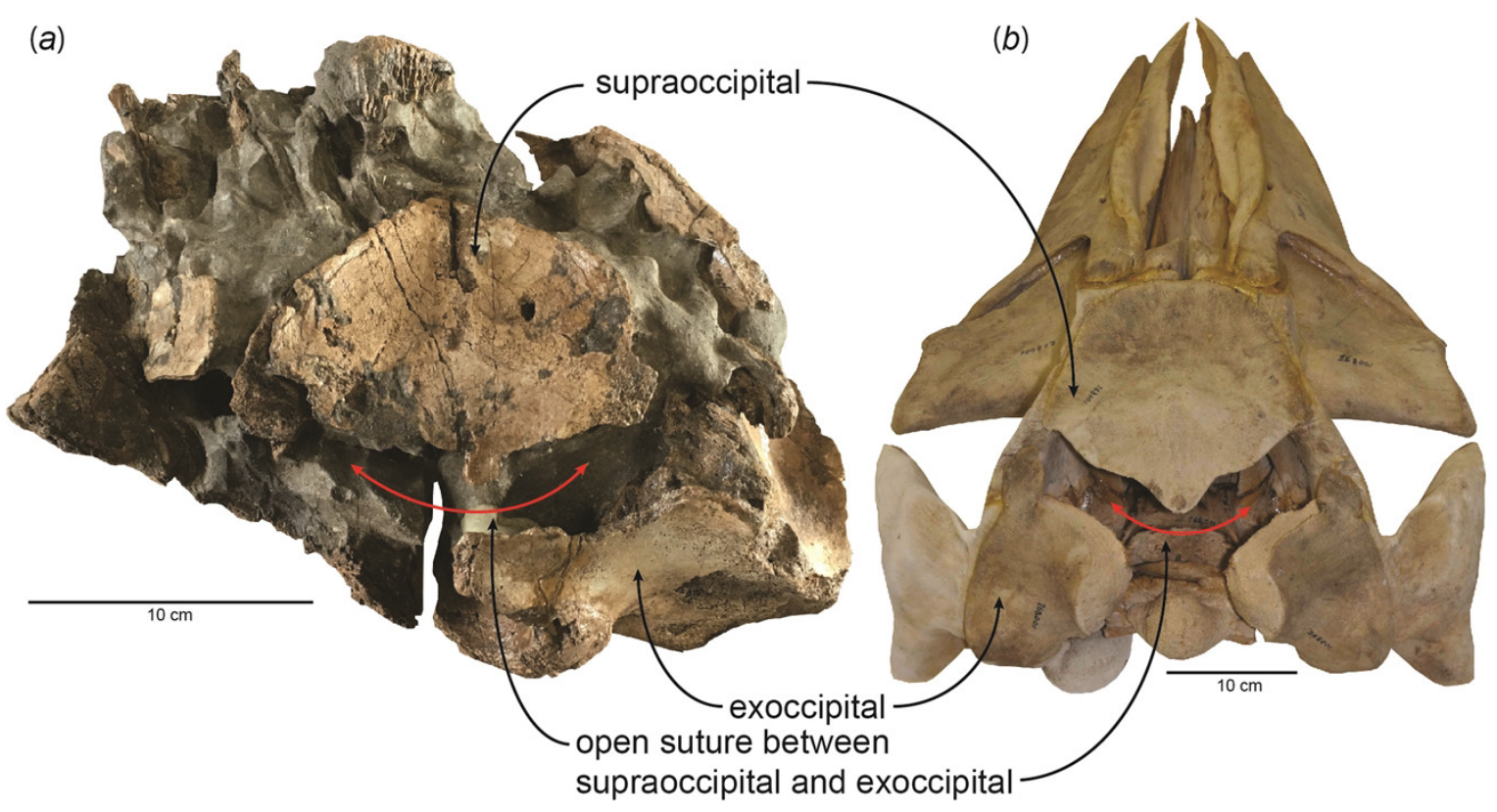

284 Figure 2. Reconstructing maps of Japan and surrounding areas during the Middle Miocene, 285 particularly ranging from 17 to $15 \mathrm{Ma}$ as this period corresponds to the geological age of HMN 286 specimens and then indicates the change of geography over time: (a) $17 \mathrm{Ma}$; (b) $16.75 \mathrm{Ma}$; (c) $28716.5 \mathrm{Ma}$; (d) 16.25 Ma; (e) $16 \mathrm{Ma}$; (f) 15 Ma. Modified from Noda and Goto, 2004. 
(a)

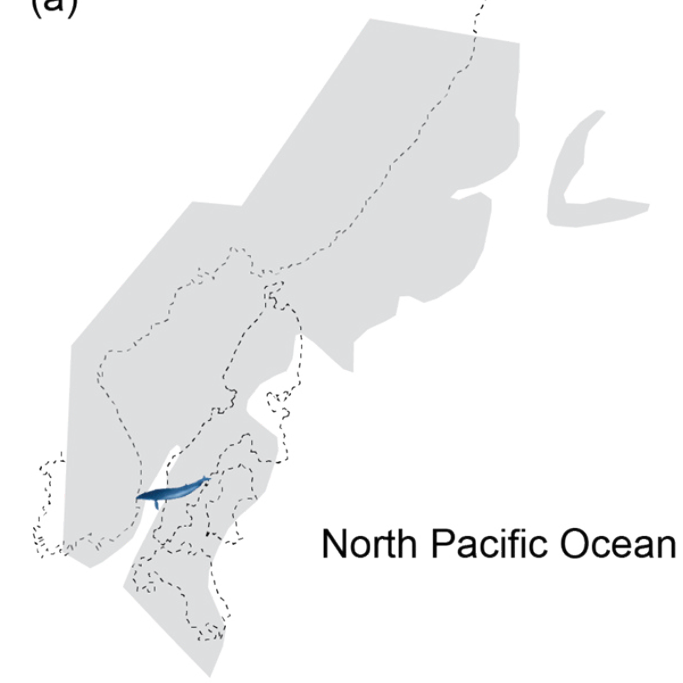

(c)

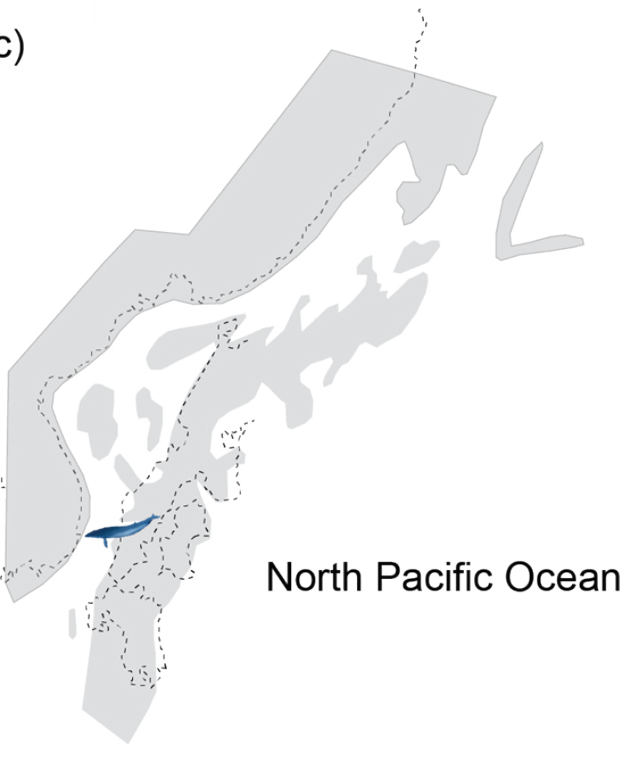

(e)

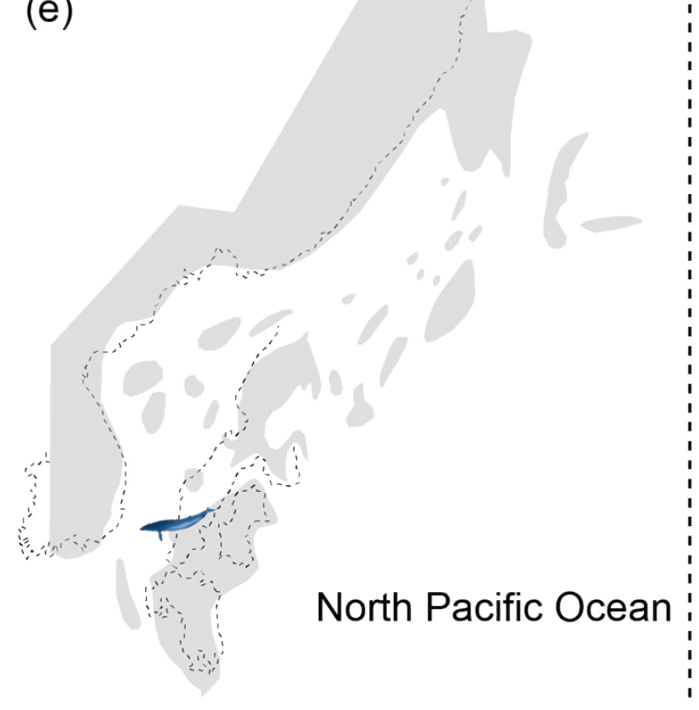

(b)

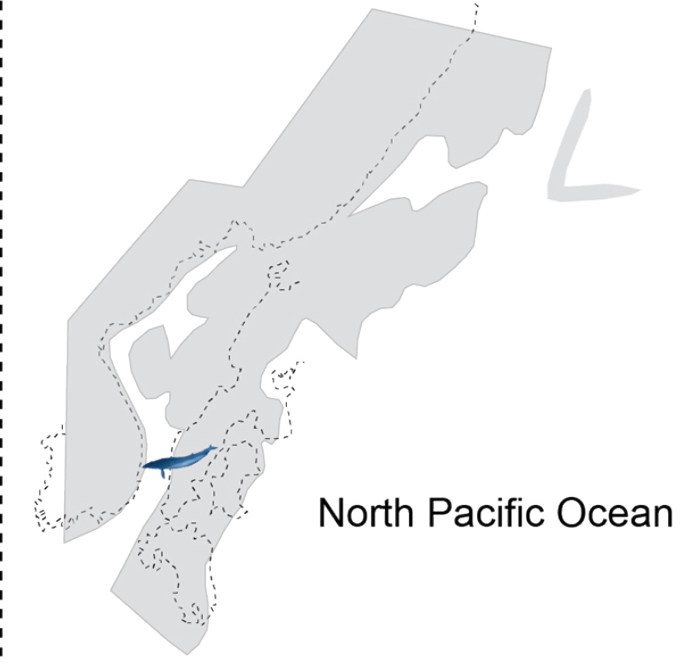

(d)

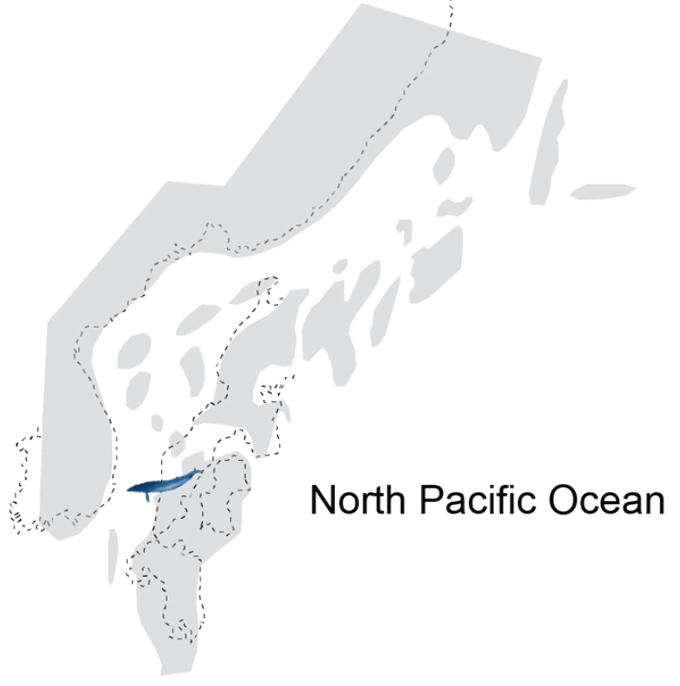

(f)

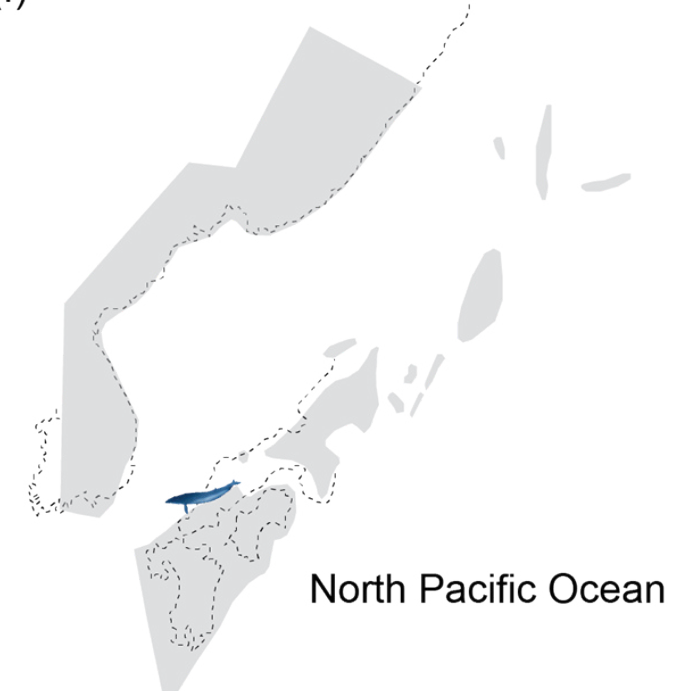


291 Figure 3. Life restoration of a mother-calf pair of Parietobalaena yamaokai (CNobumichi 292 Tamura).

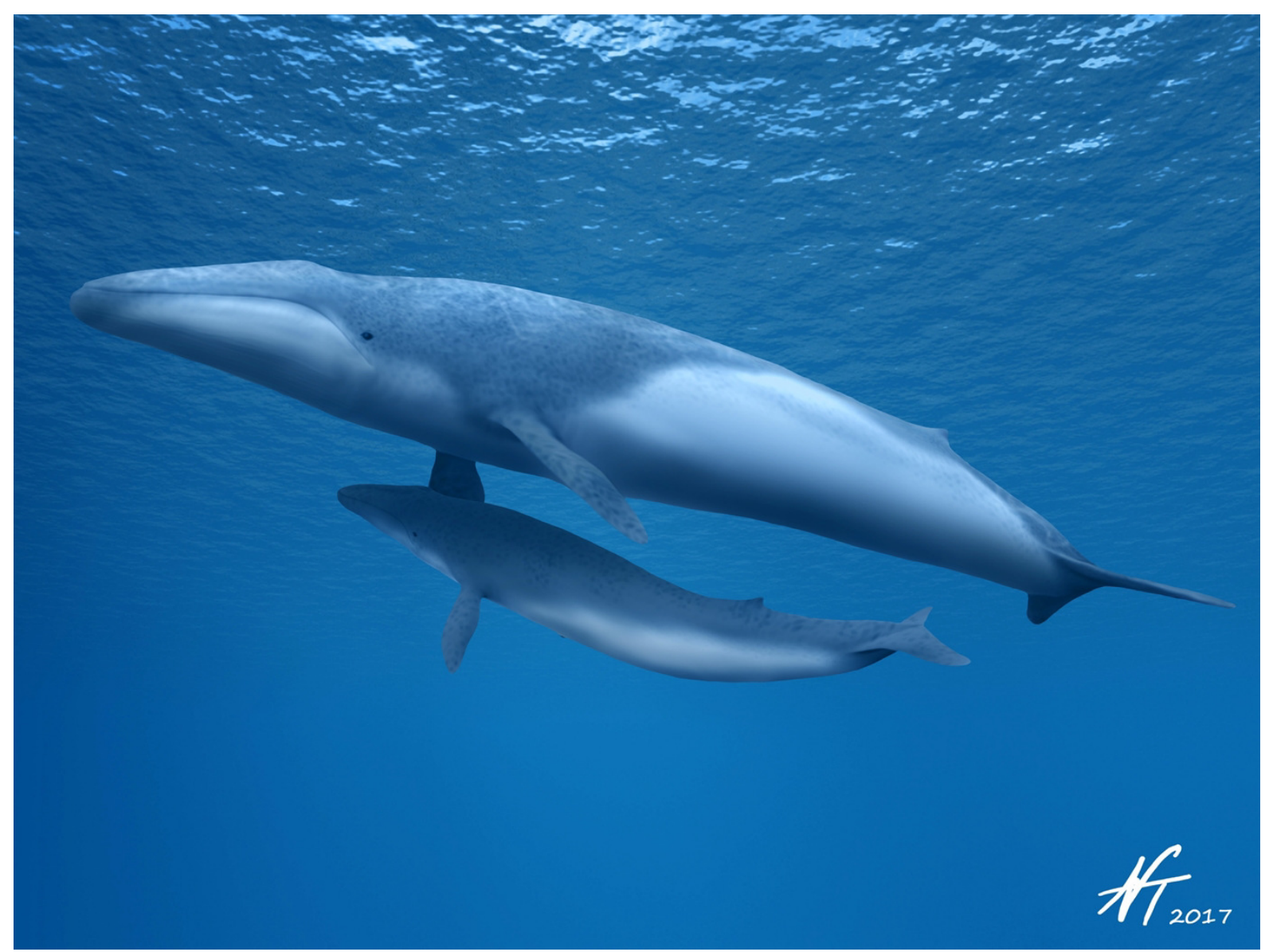

